\title{
DETECTION OF Q FEVER IN HUMAN BY POLYMERASE CHAIN REACTION TEST (PCR)
}

\author{
V.M. MAHER ALHOURANI ${ }^{*}$ A.A.EL-MONLA ${ }^{* *}$ and HIAAM BSHARA ${ }^{* * *}$ \\ ${ }^{*}$ MSC. Vet. Med. (D.V.M) in Veterinary Science, Buplic Health and preventive Medicine-Faculty of Veterinary Medicine, AL-Baath \\ University. \\ ${ }^{* *}$ Professor of Vet. Hgg. and Zoonoses, Faculty of Veterinary Medicine, AL-Baath University. \\ *** Associated Prof. Dr. in Microbiology and immunity- Faculty of medicine, AL-Baath University \\ Email: drma97@yahoo.com
}

\section{ABSTRACT}

Received at: 7/8/2014 performed to investigate the existence of $Q$ fever in human in the middle region of the Syrian Arab Republic, the study concentrated on two regions which are Hamah city and Mysiaf, in addition to some places between them, using PCR test. Coxiella Accepted: 16/11/2014 burnetii had been detected as a causative agent of Q fever with consideration that the samples were taken randomly. The prevalence rate reached at $(68 \%)$ of the human groups included in the study. This result requires High degrees of caution in order to control this disease.

Keywords: Q fever, PCR test human, Zoonosis.

\section{الكثف عن الحمّى المجهولة (Q Fever)عند الإنسان باستخدام اختبار تفاعل سلسلة البوليميراز (PCR)

$$
\text { ماهر يوسف الحورانسي، عبل الله المنلا ، هيام البشارة }
$$

Email: drma97@yahoo.com

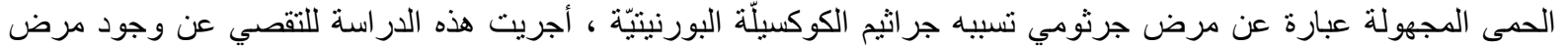

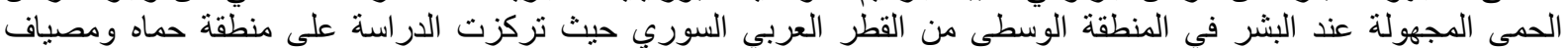

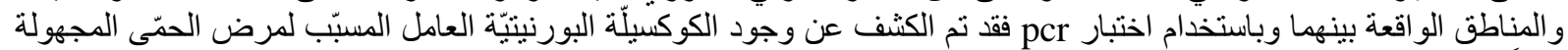

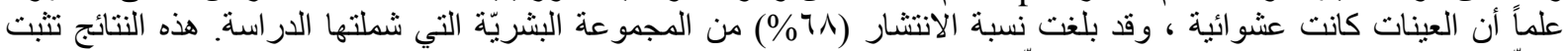

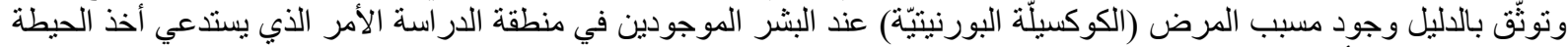
و الحذر الثنديدين لأجل التحكم بهذا المرض.
\end{abstract}

\section{INTRODUCTION المقدمـة}

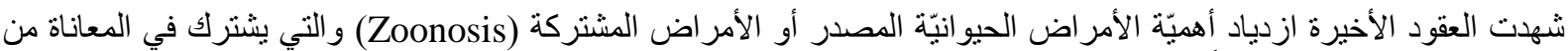

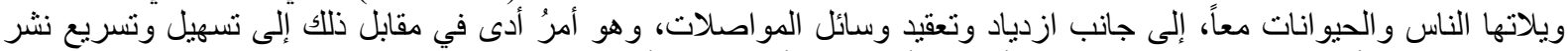

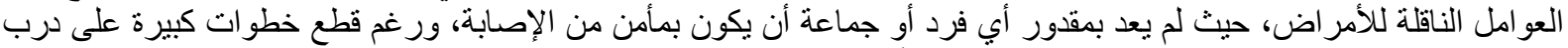

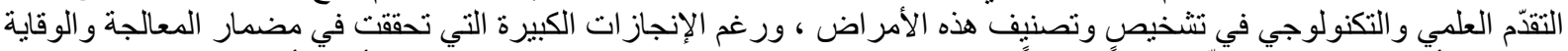

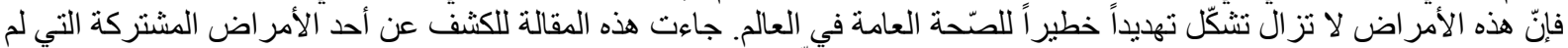

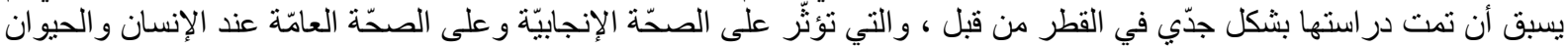

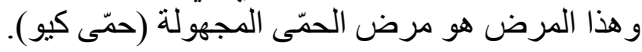

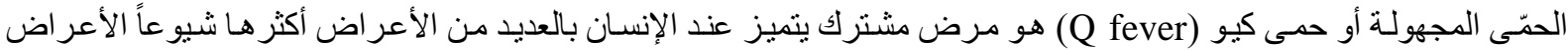

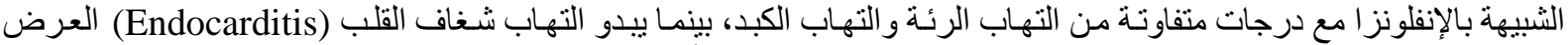

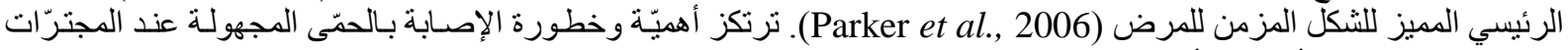

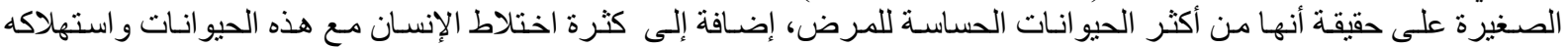

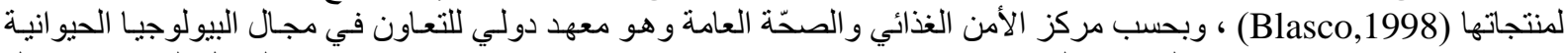

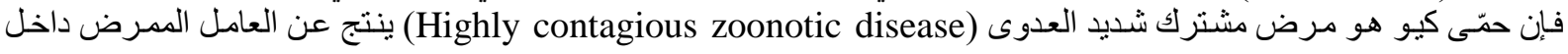




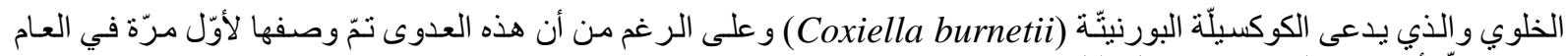

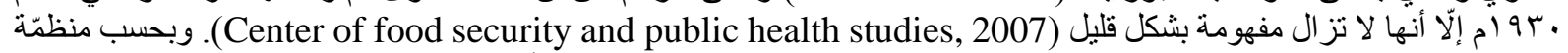

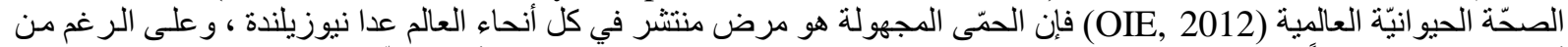

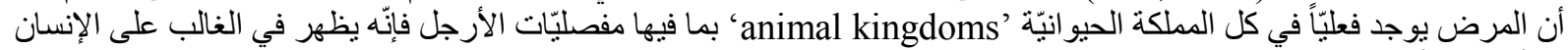

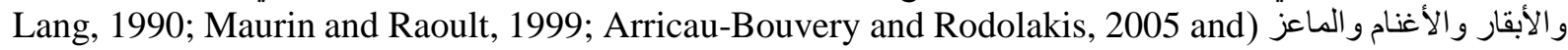

.(Anette-Bøtner et al., 2010

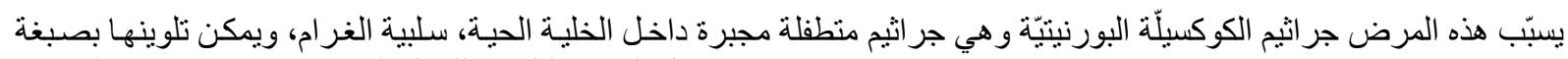

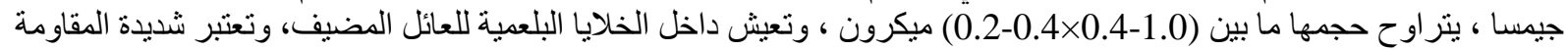

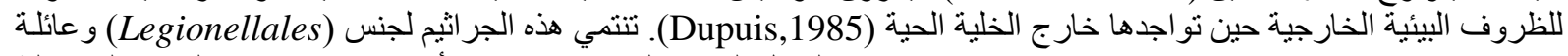
(Voth and Heinzen , 2007) (Coxiellaceae)

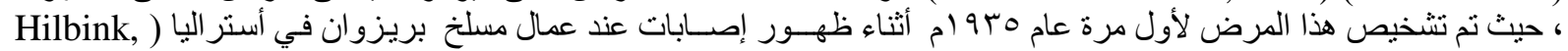

.(et al., 1993

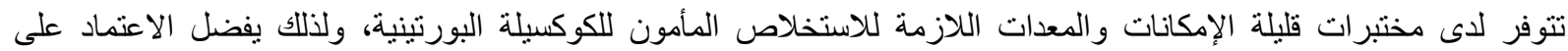

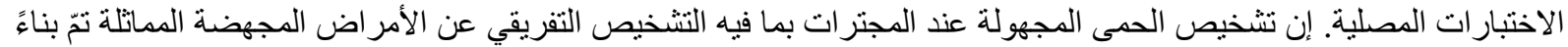

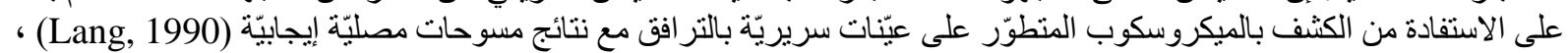

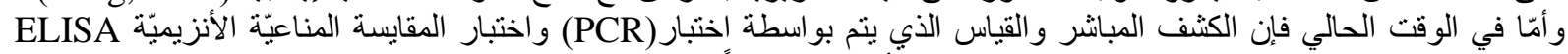

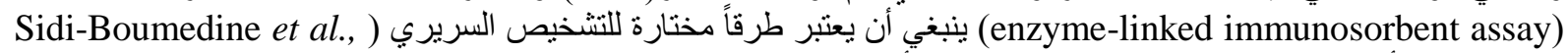

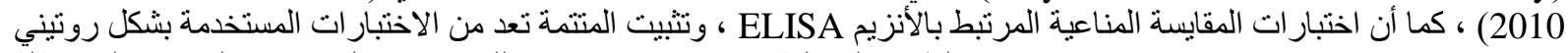

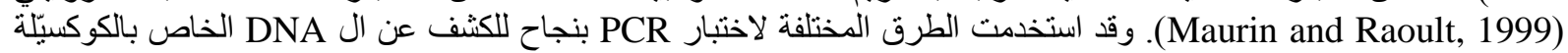

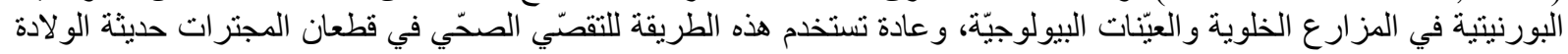

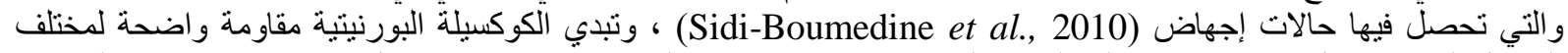

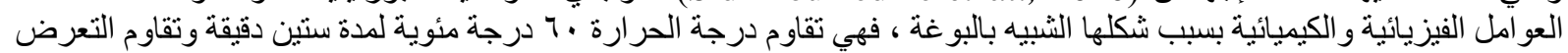

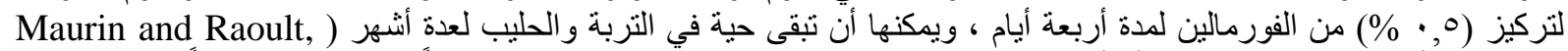

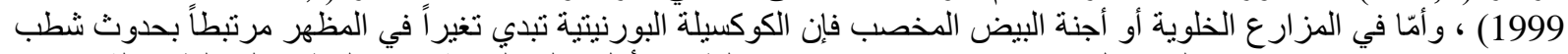

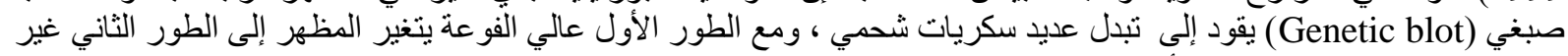

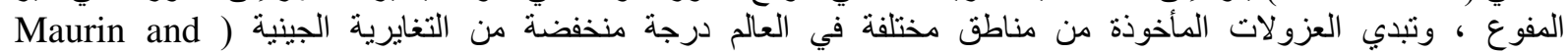
.(Raoult,1999, Raoult, 2001

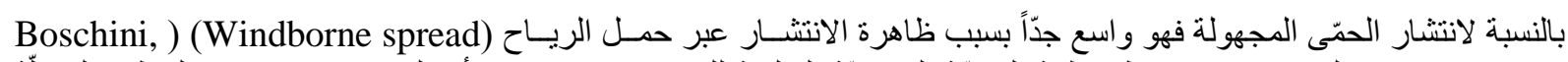

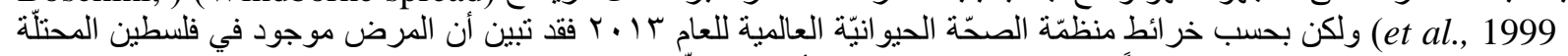

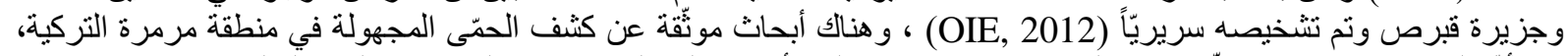

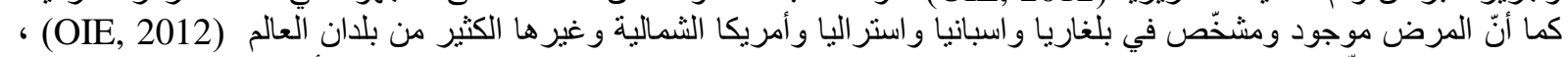

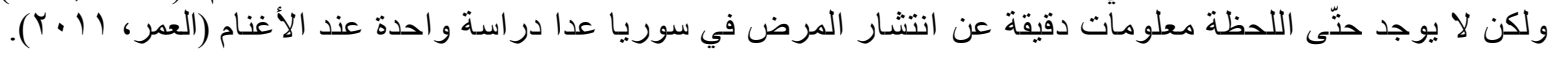

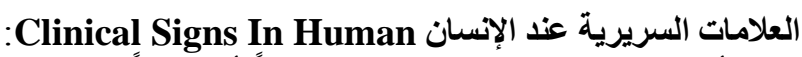

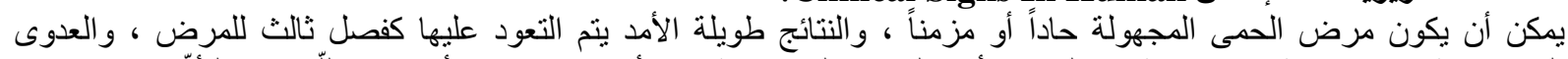

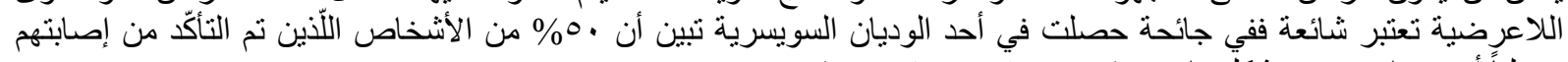

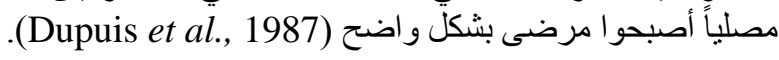

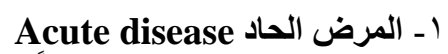

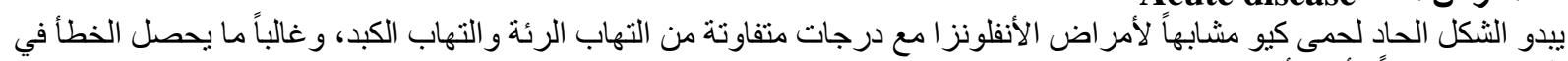

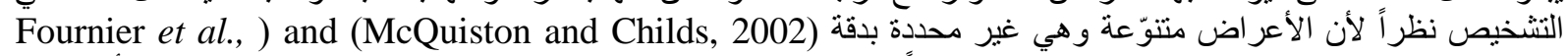

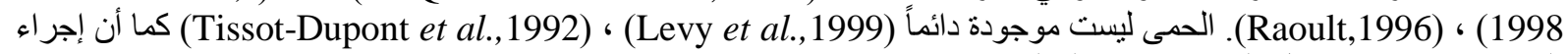

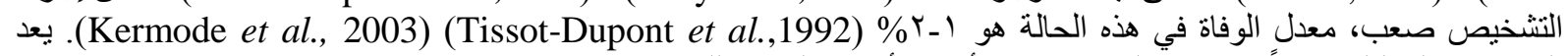
التهاب عضلة القلب نادراً (>1>\%)، لكنه و احد من أكثر الأسباب المؤدية للوفاة (Fournier et al., 2001).

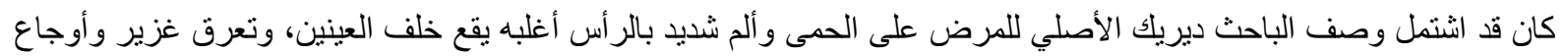

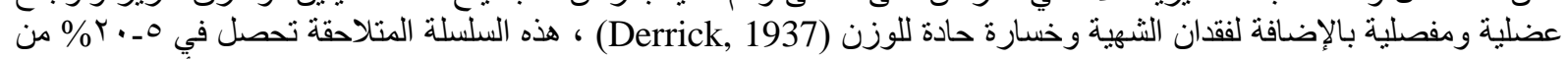

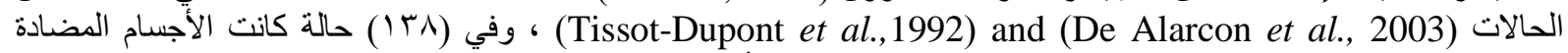

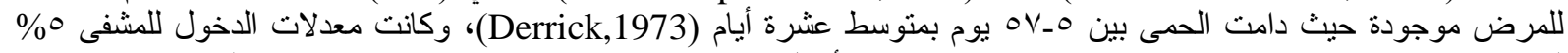

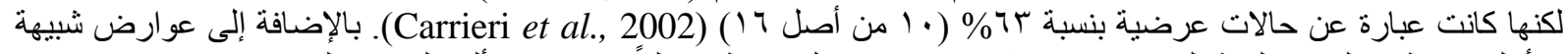

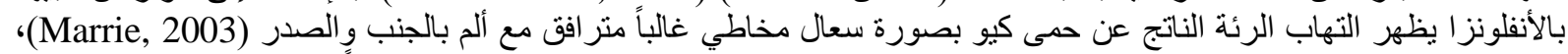

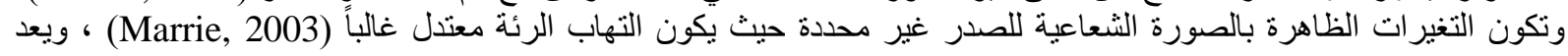




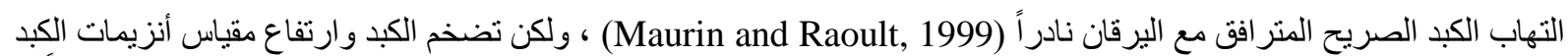

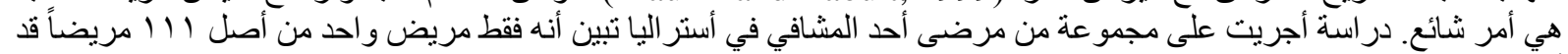

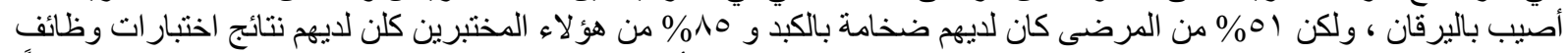

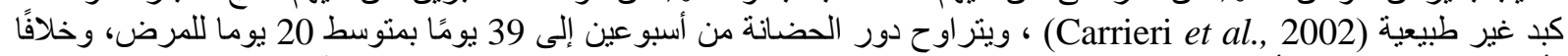

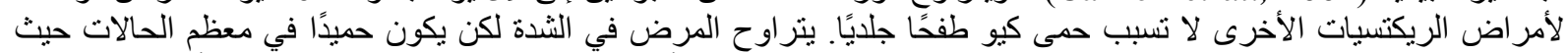

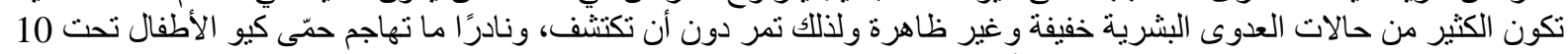

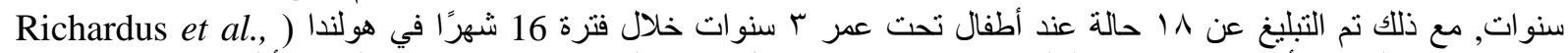

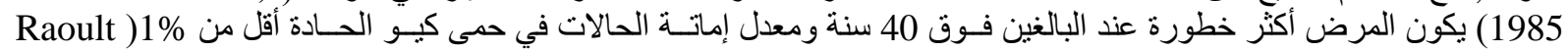

. et al., 2000

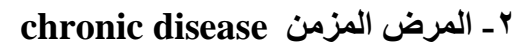

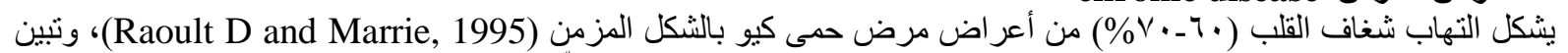

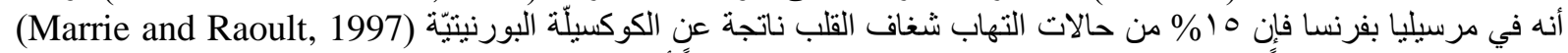

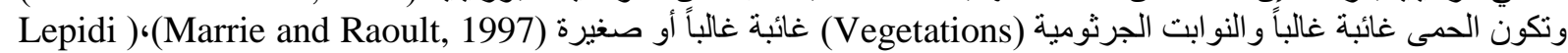
.et al., 2003

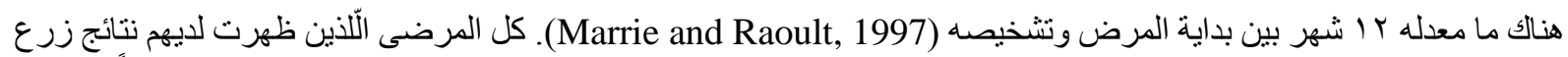

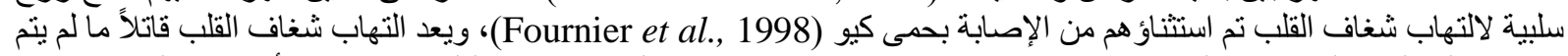

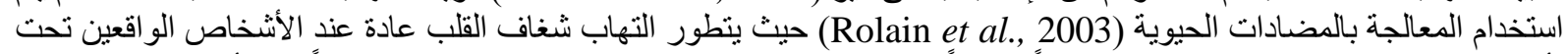

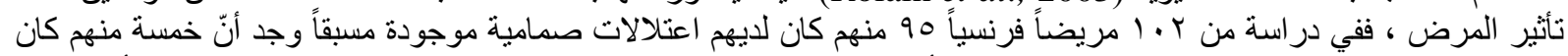

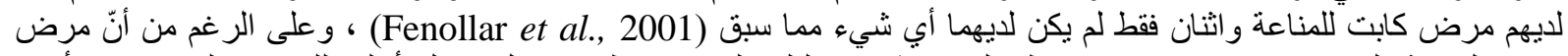

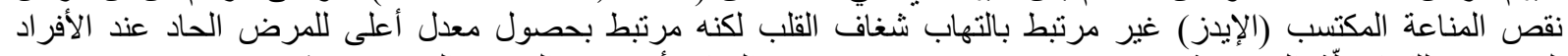

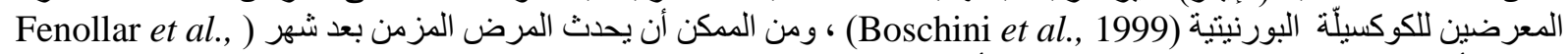

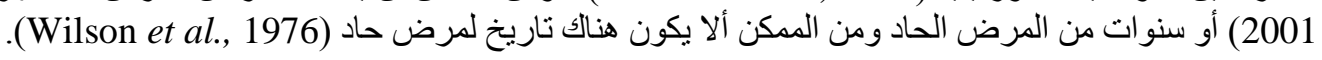

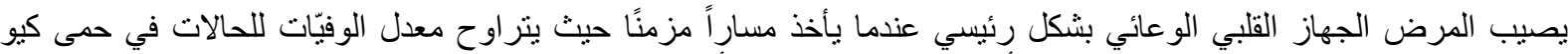

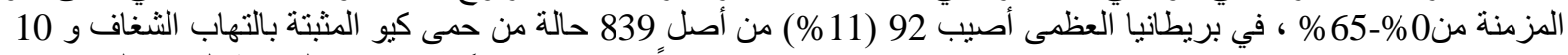

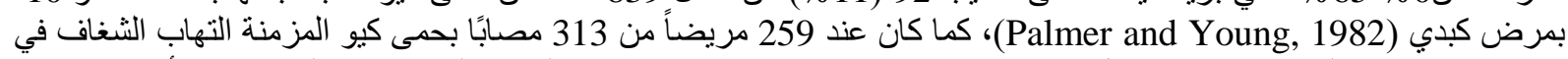

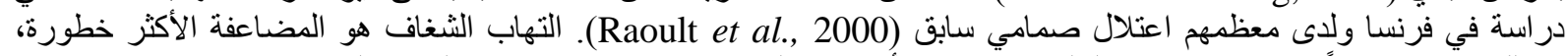

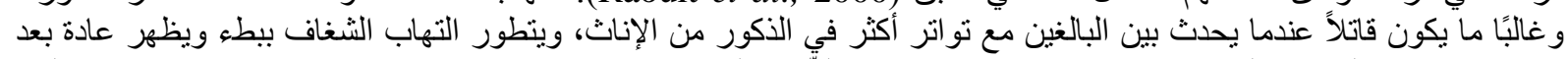

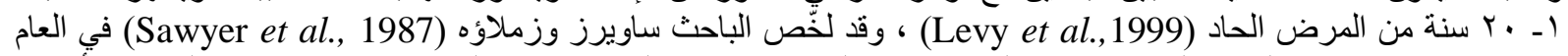

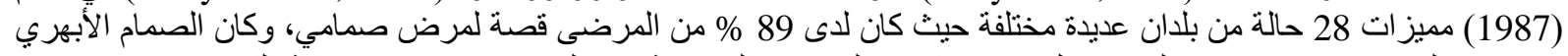

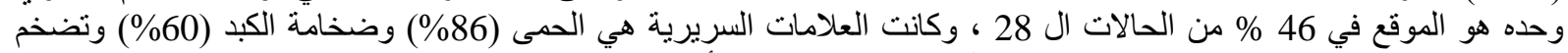

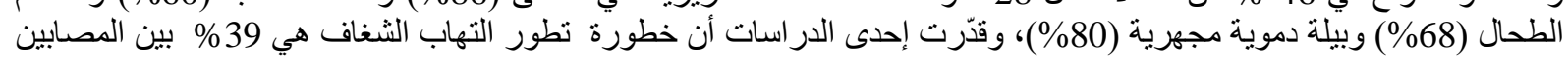

بحمى كيو مع عيوب صمامية (Fenollar et al., 2001).

\title{
MATERIALS and METHODS \\ مواد وطر ائق العمل
}

\author{
أولاً مواد العمل: Materials

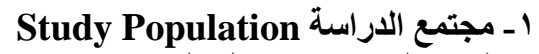 \\ عن الكوكسيلّة البورنيتيّة فيها.
}

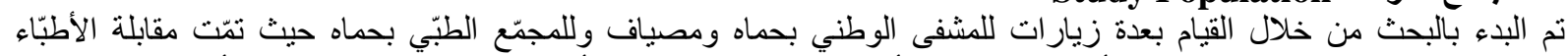

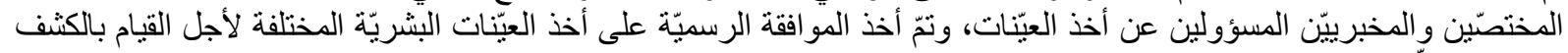

r - بمع البيانات: Collecting Data

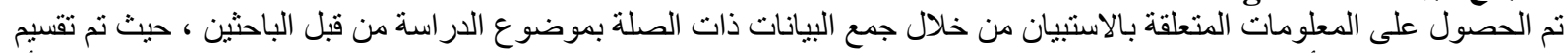

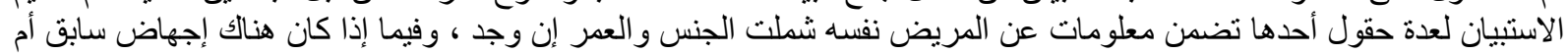

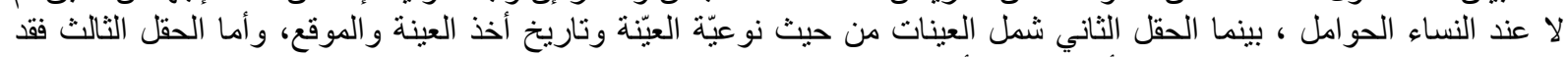

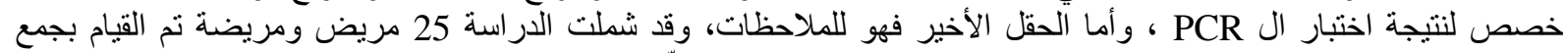

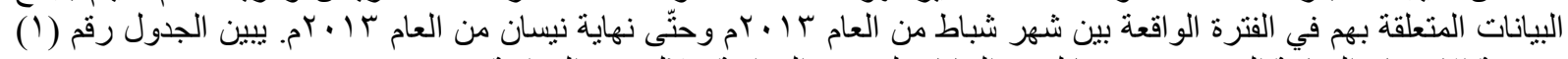

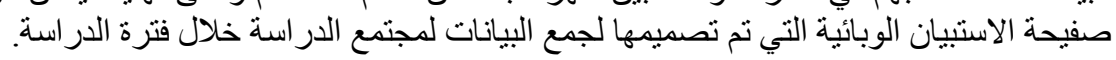


جدول رقم 1: ورقة استبيان للعيّات المشمولة بالدر اسة خلال الفترة الواقعة بين بداية شهر شباط من العام با ـ بم وحتّى نهايـة نيسان

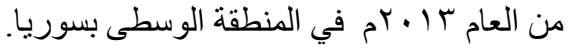

\begin{tabular}{|c|c|c|c|c|c|c|c|c|}
\hline \multirow{2}{*}{ ملاحظــات } & \multirow{2}{*}{ اختبار PCR } & \multicolumn{3}{|c|}{ العيّنات } & \multicolumn{3}{|c|}{ المريض } & \multirow{2}{*}{ رقم العيّتة } \\
\hline & & تاريخ أخذ العينة & المـوقع & نوع العيّة & وجود إجهاض & العمر & الجنس & \\
\hline & & & & & & & & 1 \\
\hline & & & & & & & & r \\
\hline
\end{tabular}

نثانياً_ طرائق العمل: Materials

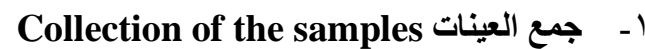

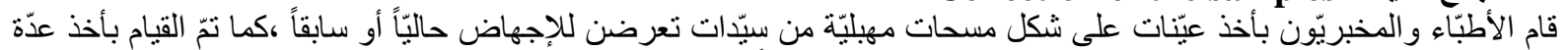

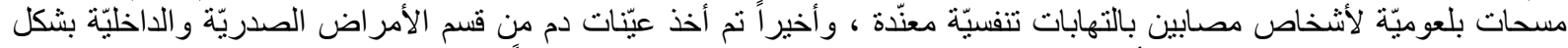
عشو ائي وتثّت معاملة هذه العيّات لأجل استخلاص الكريّات البيضاء منها حيث سيتم لاحقاً اجر اء اختبار (PCR) عليها.

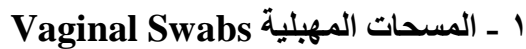

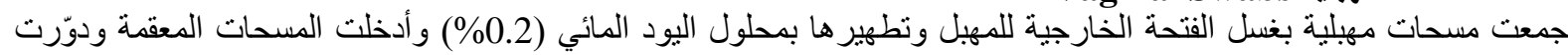
بشكل دائري داخل المهيل ونقلت إلى المختبر في حافظة مبردة (Alton et al., 1975).

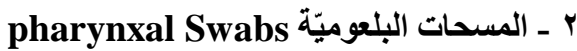

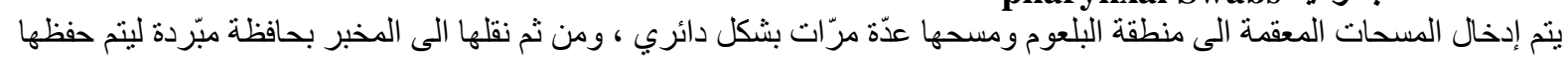
بالبرودة لحين الاستخلاص (Alton et al., 1975).

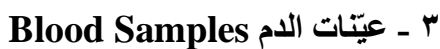

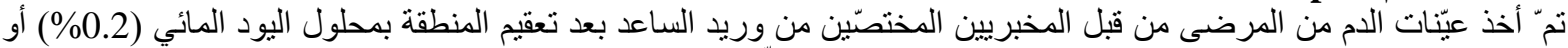

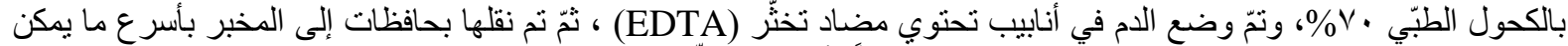

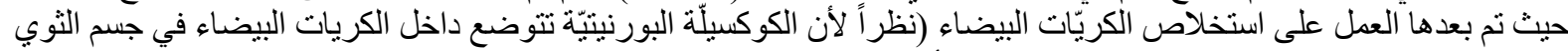
حيث تتكاثر ثم تفجّر الكريّة البيضاء لكي تهاجم خلايا أخرى) (Alton et al.,1988).

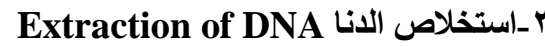
1 استخلاص الانا من المسحات Extraction of DNA from Swabs

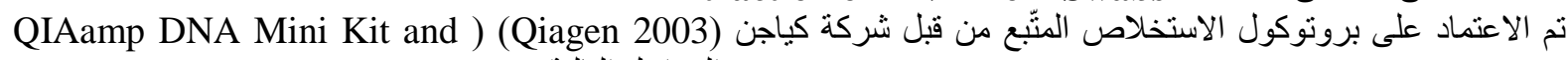

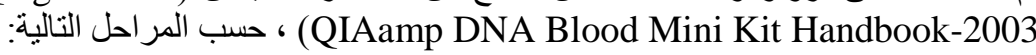

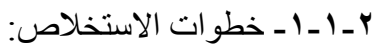

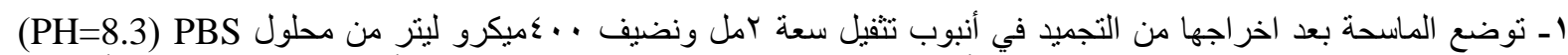

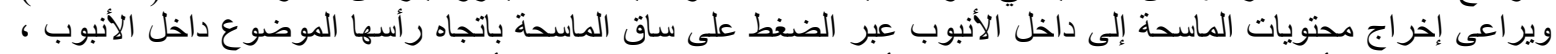

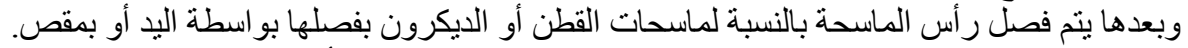

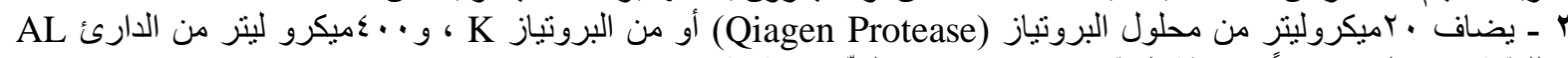

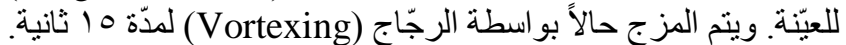

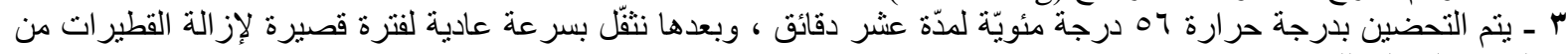

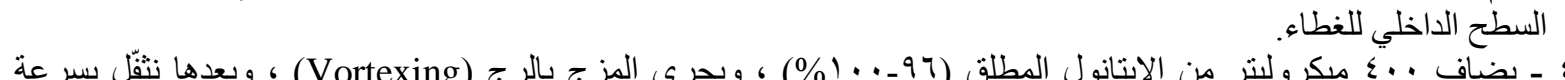

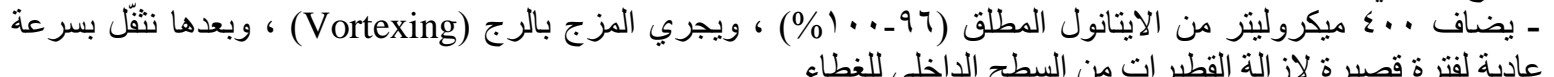

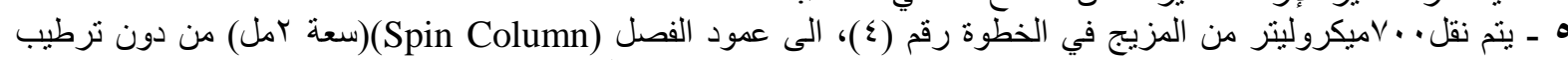

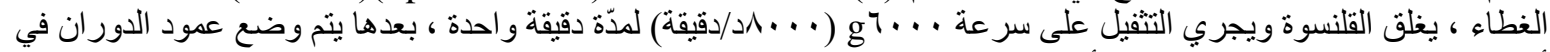

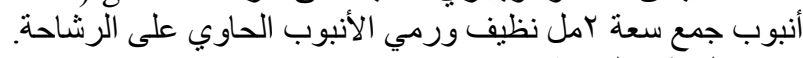

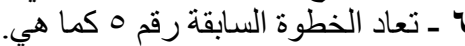

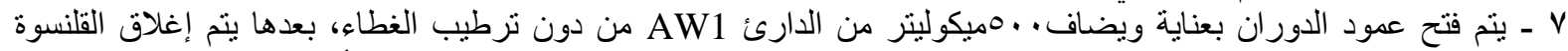

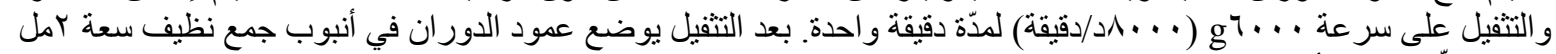
وينم التخلّص من الأنبوب الحاوي على الرشاحة. 
^ ـ يتم فتح عمود الدوران بعناية ويضاف . .0ميكوليتر من الدارئ AW1 من دون ترطيب الغطاء ، بعدها يتم إغلاق القلنسوة

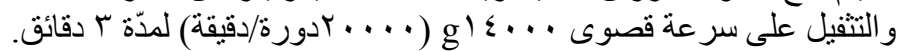

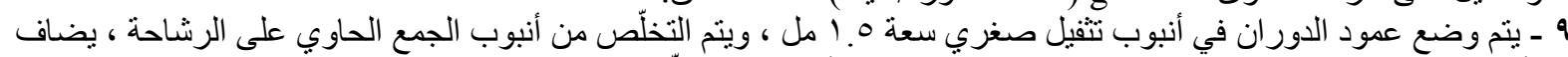

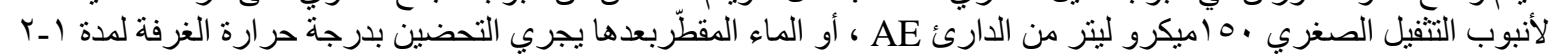

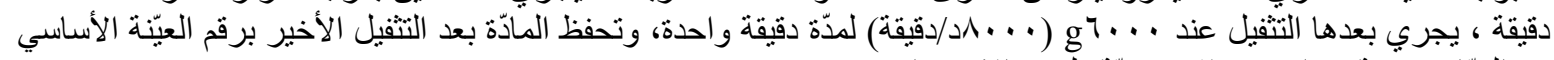

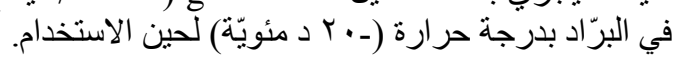

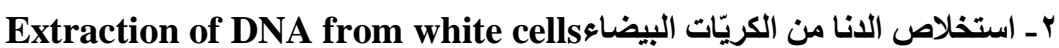

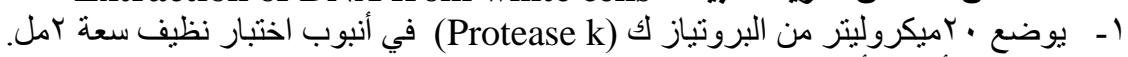

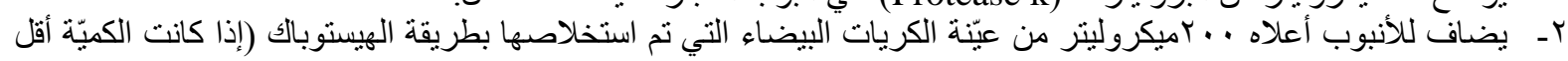

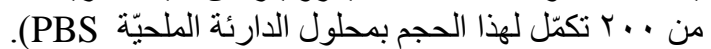

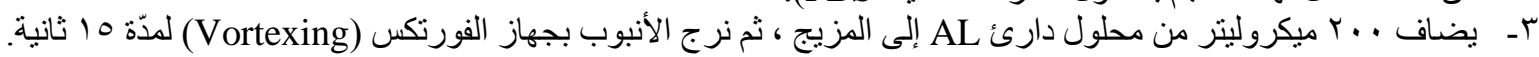

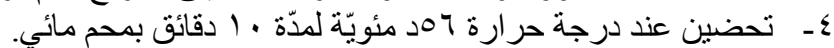

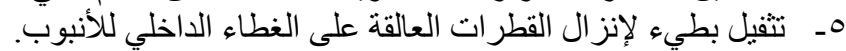

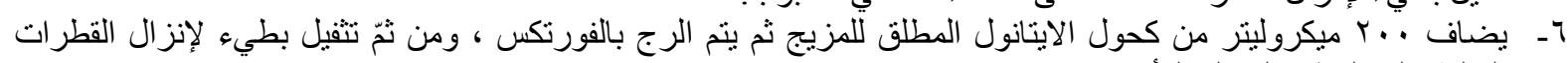

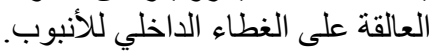

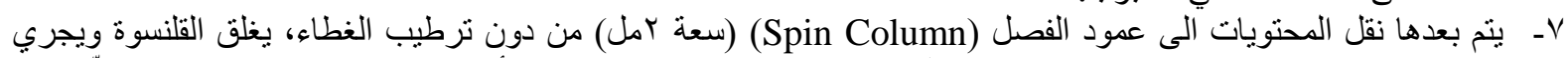

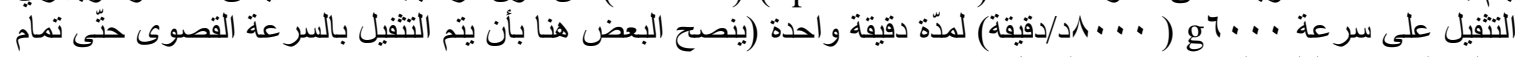
عمليّة التصفية بالفلتر الخاص بعمود الفصل).

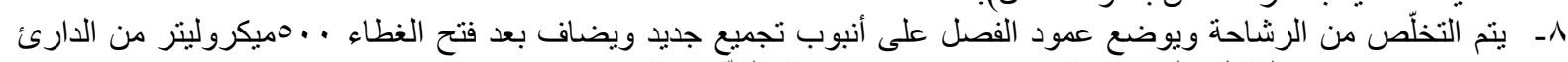

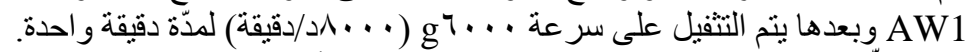

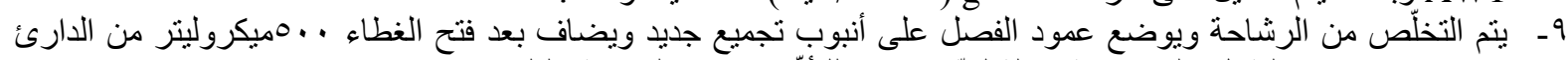

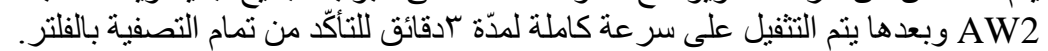

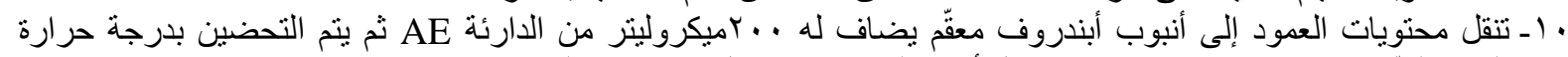

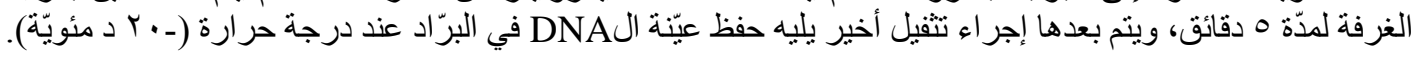

\title{
Conventional PCR for detecting of Coxiella burnetii:
}

$$
\text { r-الاختبار الرسمي للكثف عن الكوكسيّة البورنيتيّة: }
$$

\section{(AccuPrime ® Taq DNA Polymerase)}

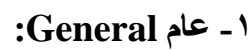

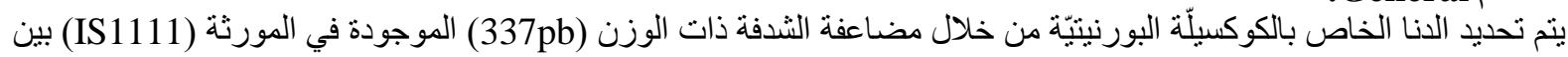

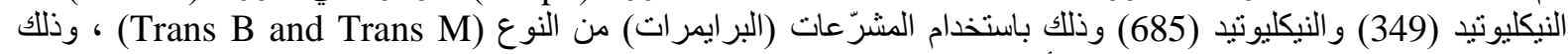

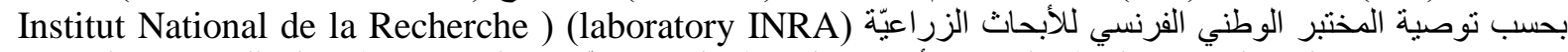

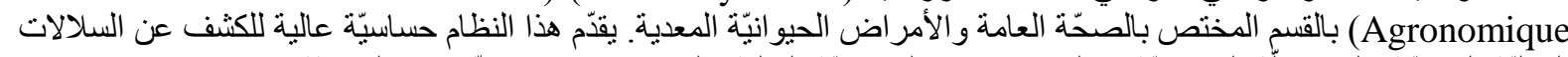

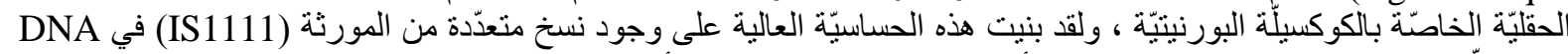

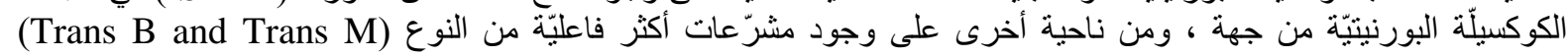

.(Alsaleh et al., 2011)

r- المواد المستخدمة في اختبار تفاعل البوليميراز المتسلسل Polymerase chain reaction Materials

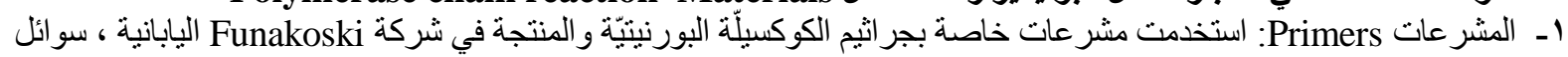

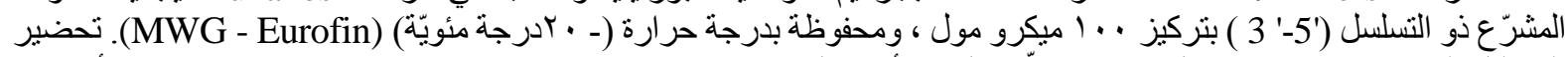

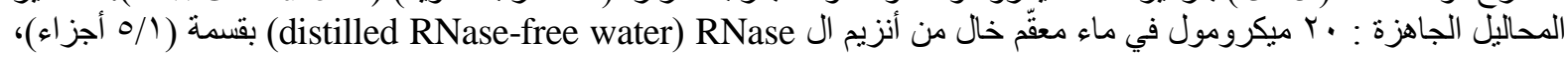

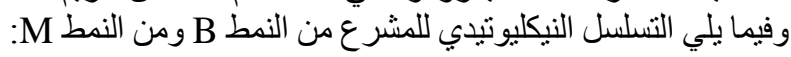

\section{- Trans B (349-371): CAA GAA TGA TAA CGA TCG TGC GC}

\section{- Trans M (664-685): CTC GTA ATC AAT ACC TTC CGC G}

\author{
(المصدر (Alsaleh et al., 2011)
}

Taq PCR Master mix 4x ب ـ عتيدة اختبار تفاعل البوليمير از المتسلسل

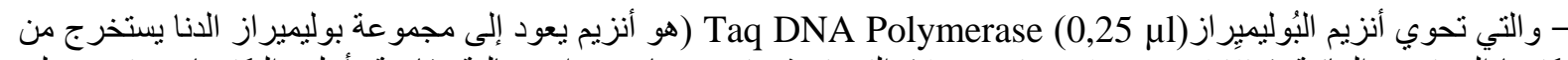

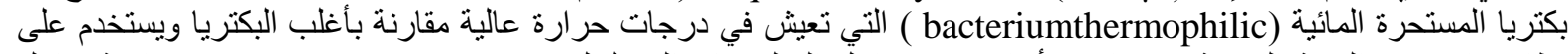
نطاق واسع في التقنية الحيوية وهو إنزبم أساسي في تفاعل البوليميراز المتسلسل) (Alsaleh et al., 2011) ، دارئة تفاعل فالغل 
البُوليميِِراز المتسلسل مع كلور التَغْنْيَيُوم (PCR Buffer with 3mM MgCl2) ، و النيوكليوزيدات منقوصة الأوكسجين ثلاثية

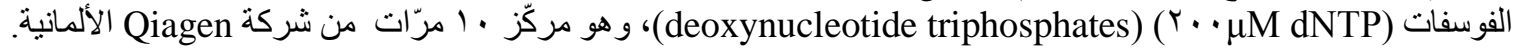

ماء - ماء مقطر خالي من DNAase ماء معقّم خال من أنزيم ال distilled RNase-free water) RNase)، استخدم في استخلاص قالب الدنا وفي تحضير مزيج

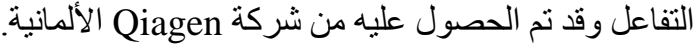

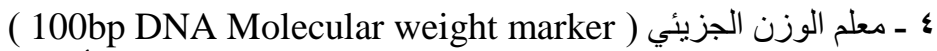
تم الحصول عليه من شركة (AB-gene) الإنجليزية و الذي استخدم من أجل معرفة الوزن الجزيئي لنواتج التفاعل

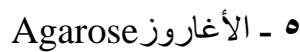
تم الحصول عليه من شركة (Peq lab) الألمانية واستخدم بتركيز ○. 1\% لغرض تحضير هلامة الأغاروز الستخدمة في الرحلان

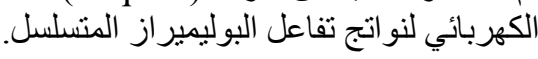

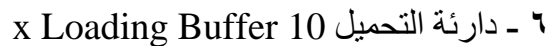
تم الحصول عليها من شركة TaKaRa اليابانية واستخدمت في حقن نواتج تفاعل البوليميراز المتسلسل عند إجراء الرحلان الكهربائي في هلامة الأغاروز.

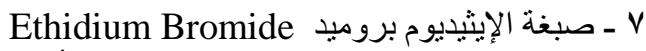

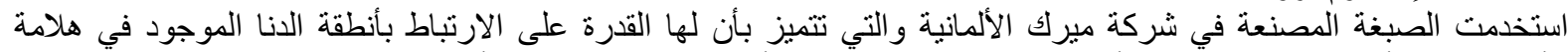
الأغاروز والتألق عند التعرض للأشعة فوق البنفجية، وقد أضيفت إلى هلامة الأغاروز والإنى دارئة الرانية الرحلان بتركيز

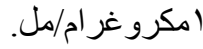

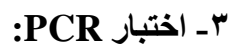

1 - تجهيز مزيج الاختبار Preparation of the PCR Mix

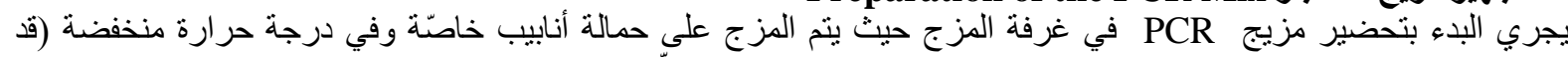

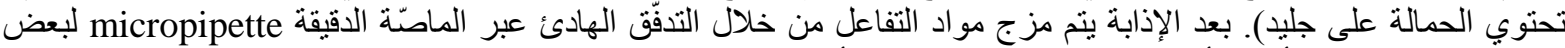

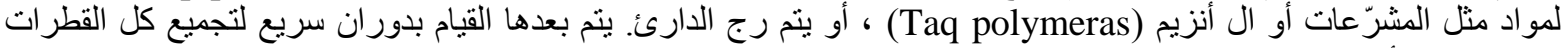

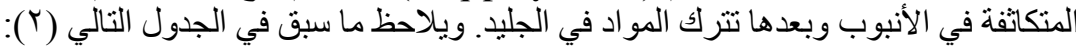
الجدول r : المو اد الداخلة في اختبار PCR مع الأحجام المستخدمة.

\begin{tabular}{ccc}
\hline Components & Volume / reaction & Final concentration \\
\hline $\mathbf{H}_{\mathbf{2}} \mathbf{O}$ RNase free & $17,75 \mu \mathrm{l}$ & \\
\hline Tampon $\mathbf{1 0} \mathbf{x}$ & $2,5 \mu \mathrm{x}$ \\
\hline TRANS B $(\mathbf{2 0} \boldsymbol{\mu M})$ & $0,75 \mu 1$ & $0,6 \mu \mathrm{M}$ \\
\hline TRANS M $(\mathbf{2 0} \boldsymbol{\mu M})$ & $0,75 \mu 1$ & $0,6 \mu \mathrm{M}$ \\
\hline Taq Polymérase & $0,25 \mu 1$ & $1,25 \mathrm{U}$ \\
\hline Total mix & $22 \mu 1$ & \\
\hline
\end{tabular}

ـ يتم سحب ب r ميكرومول من المزيج بماصّة ووضعها في أنبوب صغير سعة (r · مل) ، وتحفظ هذه الأنابيب بالجليد لحين إضافة العينّات.

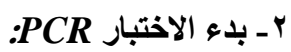

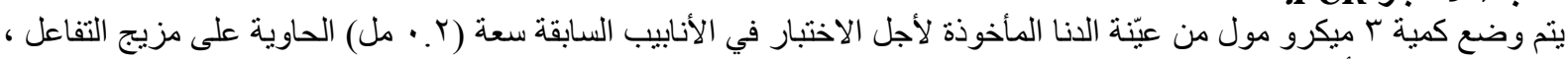

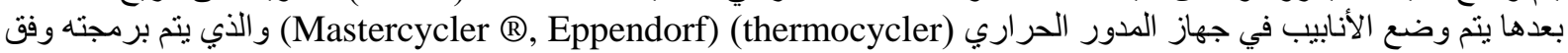

النظام التالي في الجدول (بآ). 
الجدول r النظام الحراري المستخدم في جهاز الدور الحراري.

\begin{tabular}{cccc}
\hline Activity & Temperature $\left({ }^{\circ} \mathbf{C}\right)$ & Time (min) & Number of cycles \\
\hline Initial denaturation & 94 & 10 & 1 \\
\hline Denaturation & 94 & $30 \mathrm{sec}$ & 35 \\
\hline Hybridization & 63 & 1 & 35 \\
\hline Elongation & 72 & 3 & 35 \\
\hline Final elongation & 72 & 10 & 1 \\
\hline
\end{tabular}

وبحسب النظام الحراري أعلاه يتم تضخيم شدفات محدّدة من الدنا الخاص بجرثوم الكوكسيلّة البورنيتيّة ملايين المرّات ليظهر في المرحلة التالية.

\section{Analysis of amplified products by agarose gel electrophoresis:}

rـ تحليل النواتج بواسطة الفصل الكهربائي لهلام الأغاروز:

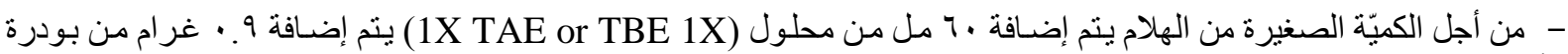
الأغاروز. - من أجل الكميّة الكبيرة من الهلام يتم إضـافة ... 1 مل من محلول (1X TAE or TBE 1X) يتم إضـافة ه. 1 غرام من بودرة الأغاروز. - يتم إذابة الأغاروز في المحلول بوضع الدورق في الميكروييف ، وير اعى تبريد المزيج بعدها الى الدرجة ـ ب درجة مئوية قبل - يتم الصب في الجهاز الخاص بالصب ويشترط أن تكون الوضعيّة أفقيّة ، ويترك الهلام ليتصلّب حتى يصبح لونه كامد (يفقد شفافيتّه). - يتم صب الدارئ TAE or TBE على الهلام المتصلّب.

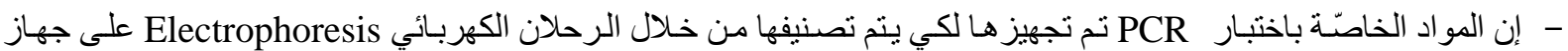

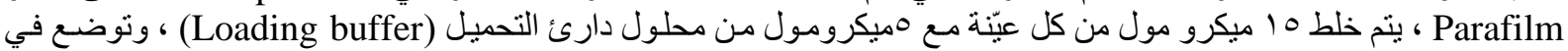
داخل الحفر المناسبة داخل الهلام.

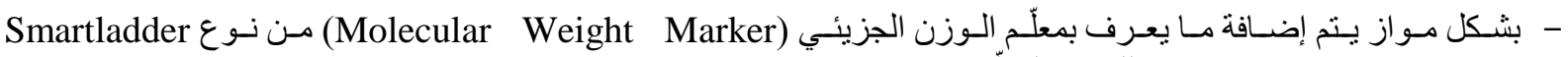
(Eurogentec, Belgium)

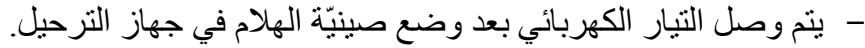
- يتم الرحلان لمدّة 10 دقيقة على كمون • ب فولط ، ثم لمدة ساعة وربع على كلى كمون • 1 فولط، ويستمر الرحلان حتّى تصل سو ائل

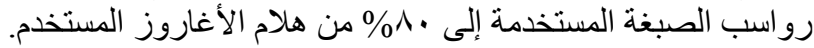

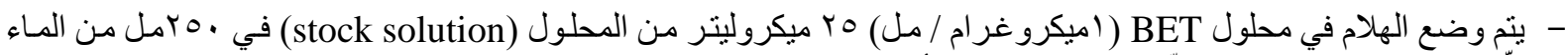

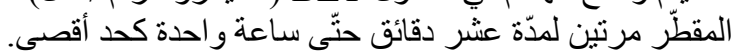

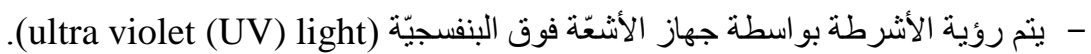

ع ع قراءة وتحليل اختبار ال PCading and interpretation of PCR :PCR

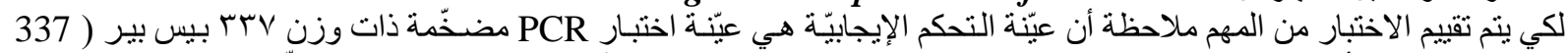

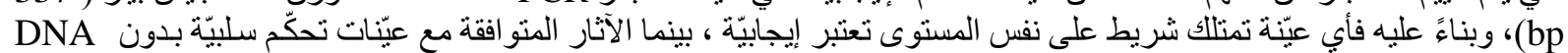
يجب أن لا تحتوي أي شريط.

\section{DISCUSSION and RESULTS النتائسج و والمناقثة}

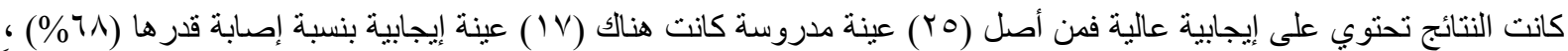

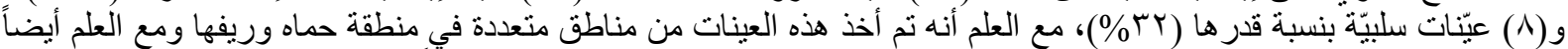

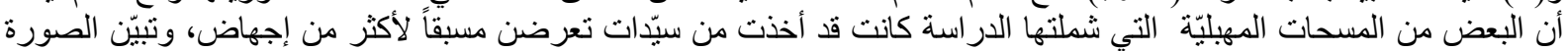

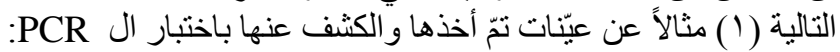




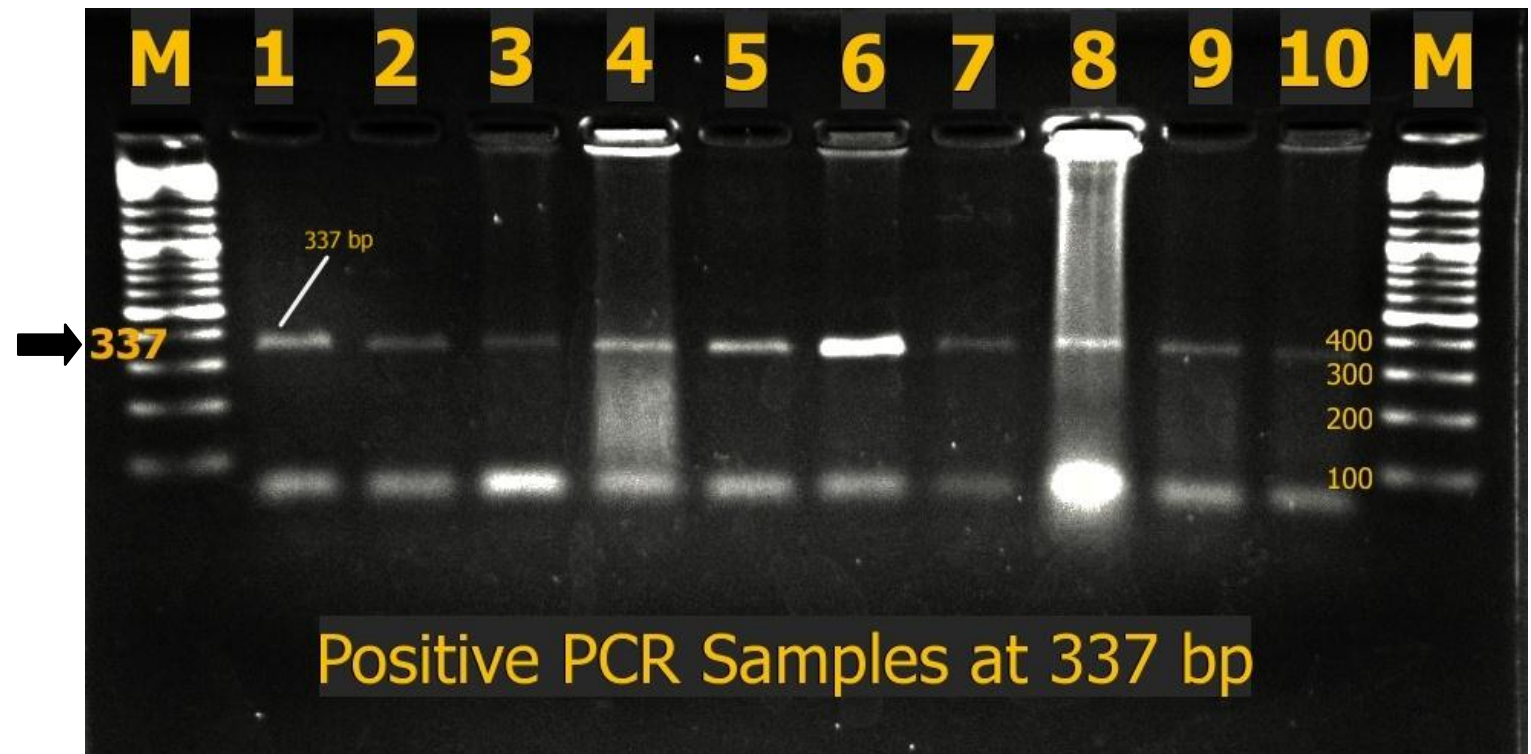

الصورة ( ): نتيجة اختبار الكثف عن جرثوم الكوكسيلّة البورنيتيّة باختبار PCR حيث تكون العيّنة الإيجابيّة هي عيّنة اختبار PCR (337)

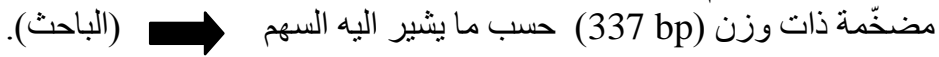

و على اعتبار أن نسبة الإصابة بالحمى المجهولة في هذه الدراسة كانت (^^\%) فقد تم حساب الخطأ المعياري في هذه النسبة وفقاً

$$
S E(P)=\sqrt{\frac{P(1-P)}{n}}
$$

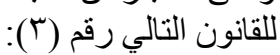

حيث أن القيمة (0.68=p) تعبر عن نسبة انتشار الحمى المجهولة في المجموعة البشرية المدروسة، وبالنتيجة فقد كانت قيمة الخطأ The Confidence المعياري (SE

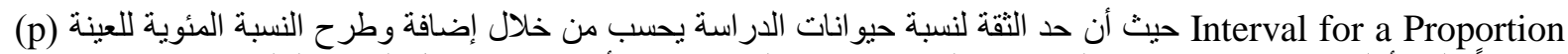
مضروباً بالخطأ المعياري و هكذا فإن حد الثقة 95\% لنسبة حيو انات الدراسة يمكن أن يقدر من خلال القانون التالي رقم (؟) :

$$
\begin{aligned}
& P \mp 1.96 \times S E(P)= \\
& \left\{P-1.96 \sqrt{\frac{P(1-P)}{n}}, P+1.96 \sqrt{\frac{P(1-P)}{n}}\right\}
\end{aligned}
$$

تم حساب قيمة الخطأ المعباري ( SE(P)=0,07 ) وبناءً على القانون السابق و على اعتبار أن قيمة p = 0.68 فقد تم حساب حد

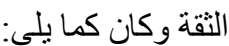

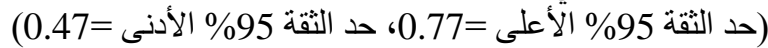

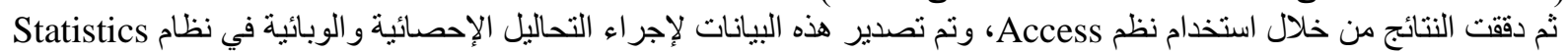
النسخة.r. (Analytical Software@ 1998)

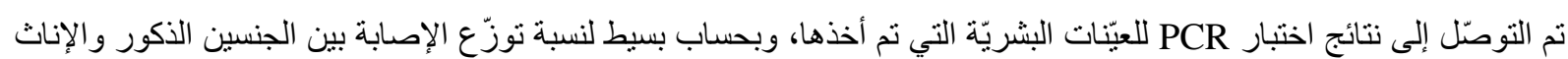

\begin{tabular}{|c|c|c|c|c|c|c|}
\hline المجموع \% & المجموع & سلبي \% & سلبي & إيجابي \% & إيجابي & \\
\hline$\% \varepsilon \varepsilon$ & 11 & $\% \wedge$ & r & $\%$ \% & 9 & ذكور \\
\hline$\% 04$ & $1 \varepsilon$ & $\% r \varepsilon$ & 7 & $\%{ }^{H}$ & $\wedge$ & إناث \\
\hline$\% 1 \ldots$ & ro & $\% r r$ & $\wedge$ & $\% \uparrow \Lambda$ & IV & المجموع \\
\hline
\end{tabular}

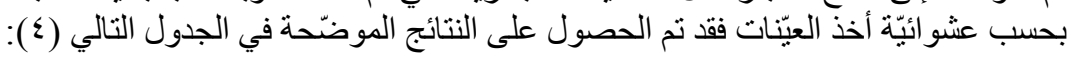
الجدول ؛ : التكر ار المطلق والنسبة المئوية للإصابة بالحمى المجهولة عند مجتمع الدراسة. 
Assiut Vet. Med. J. Vol. 60 No. 143 October 2014

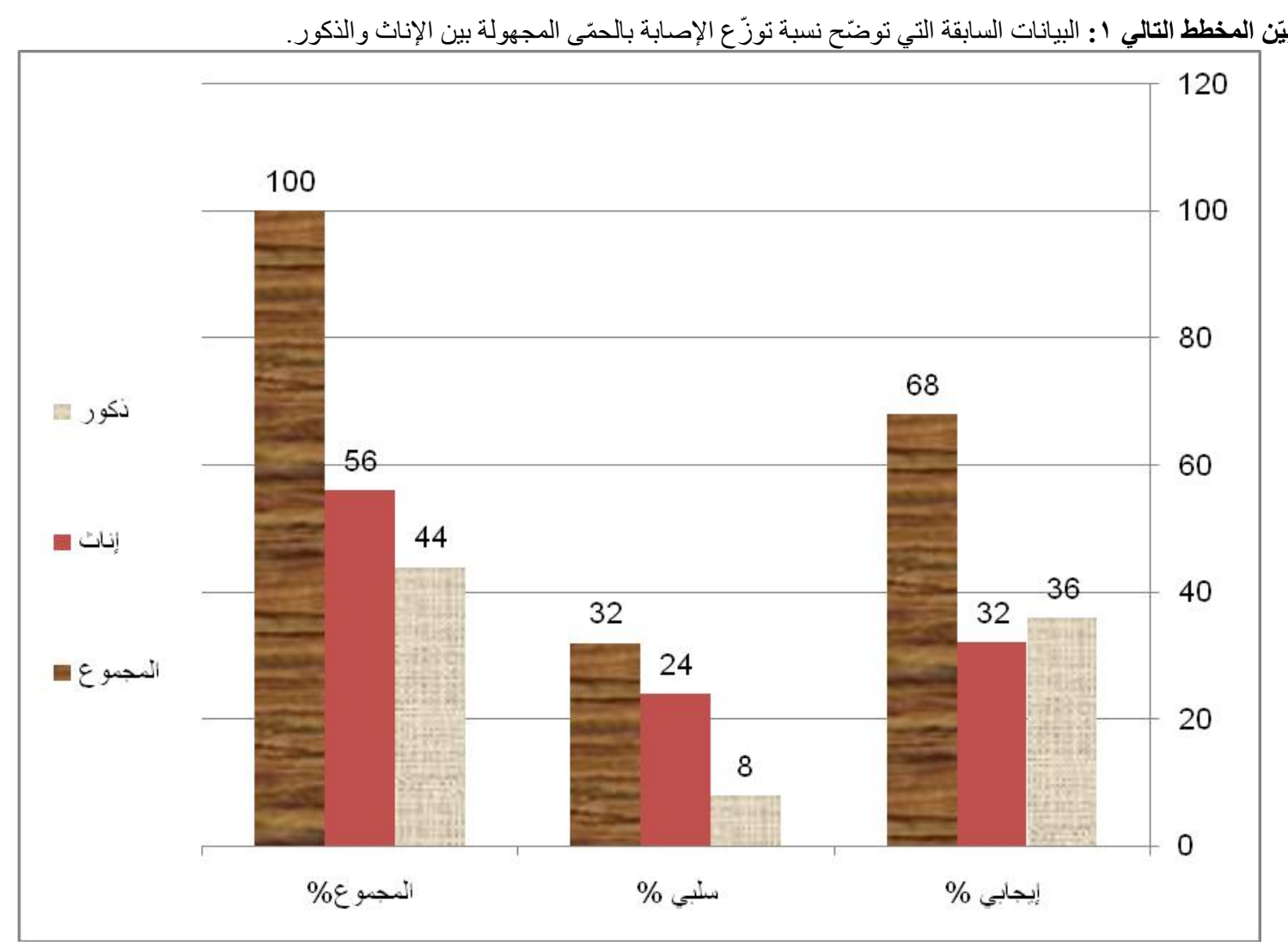

المخطط (1 ): نسبة توزّع الإصابة بالحمّى المجهولة بين الإناث و الذكور

وبالنسبة لتوزّع النتائج بحسب نوع العيّنات فقد تم الحصول على النتائج الموضّحة في الجدول التالي (0):

الجدول ه: التكر ار المطلق و النسبة المئوية للإصابة بالحمى المجهولة بحسب نوع العيّنات عند مجتمع الدراسة.

\begin{tabular}{|c|c|c|c|c|c|c|c|c|}
\hline المجموع (\%) & المجموع & 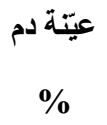 & عيّتة دم & بلعوميّة \% مسحة & مسحوميّة & مسحة مهبليّة & مسحة مهبليّة & \\
\hline$\% 7 \wedge$ & 11 & $\% \varepsilon$ & 1. & $\% \wedge$ & r & $\% r$. & 0 & إيجابي \\
\hline$\%$ \%r & V & $\%$ T & 7 & $\%$. & · & $\% \wedge$ & r & سلبي \\
\hline$\% 1 \ldots$ & ro & $\%\urcorner \varepsilon$ & 17 & $\% \wedge$ & r & $\%$ Yᄉ & v & المجموع \\
\hline
\end{tabular}

ويبيّن المخطّط التالي ؟ : البيانات بالنسب المئويّة لنسبة الإصابة بالحمّى المجهولة حسب نوع العيّنة المأخوذة. 


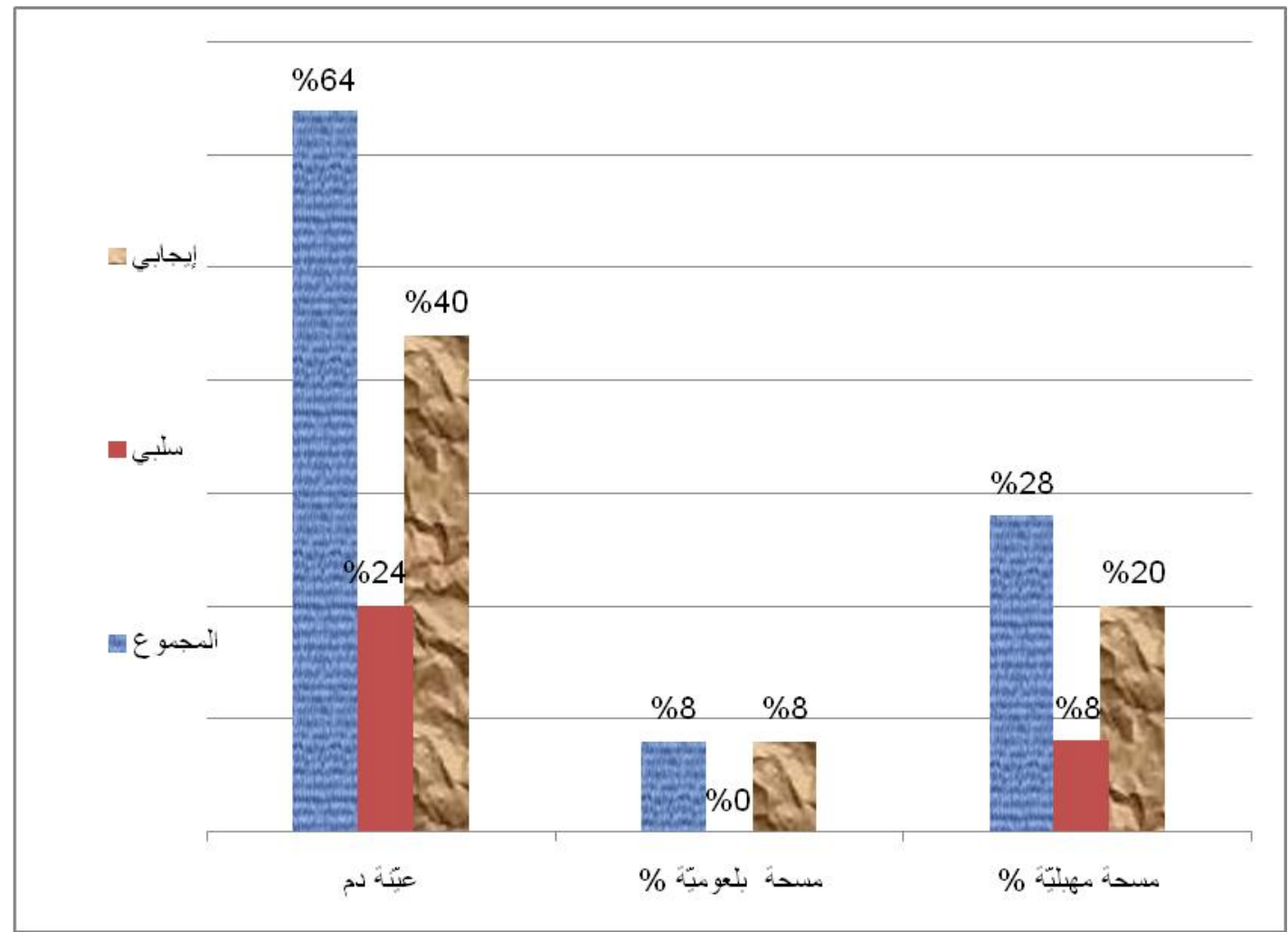

المخطّط (ץ) : البيانات بالنسب المئويّة لنسبة الإصابة بالحمّى المجهولة حسب نوع العيّنة المأخوذة

وبالنسبة للعلاقة بين الإجهاض و الحمّى المجهولة فقد نم التوصّل للجدول التالي (ج) الذي يبيّن عدد ونسبة الحالات الإيجابيّة والسلبيّة

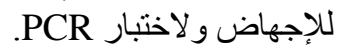

الجدول T': الذي يييّن عدد ونسبة الحالات الإيجايِّة و السلبيّة للإجهاض و لاختبار PCR.

\begin{tabular}{|c|c|c|c|c|c|}
\hline المجموع & 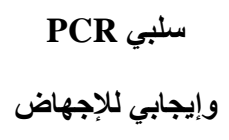 & وسلبي للاججهاض PCR & وإيجابي ولبي للاجهاض & 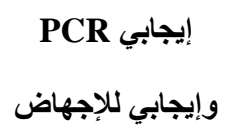 & \\
\hline $1 \varepsilon$ & r & $\varepsilon$ & $r$ & 0 & عدد العينات \\
\hline 07 & $\wedge$ & 17 & Ir & $r$. & النسبة المئوية \\
\hline
\end{tabular}

ويبيّن المخطّط بـ: العلاقة بين الإجهاض و الحمّى المجهولة كما يلي. 


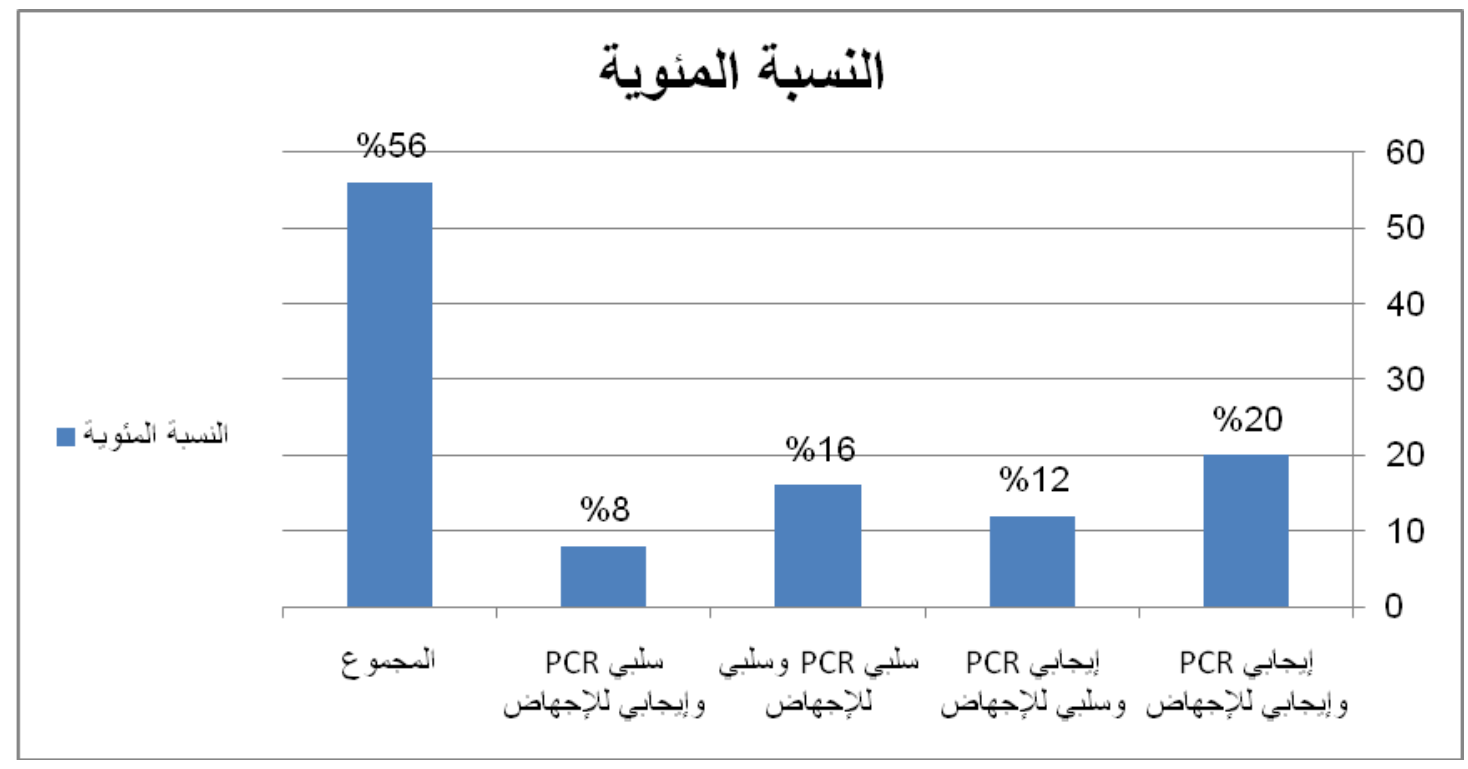

المخطّط (ب): العلاقة بين الإجهاض و الحمّى المجهولة

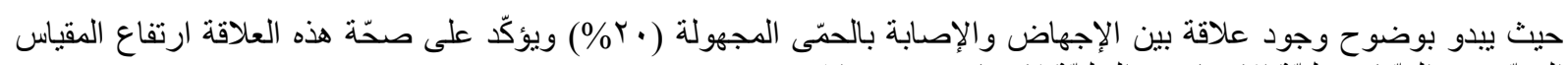

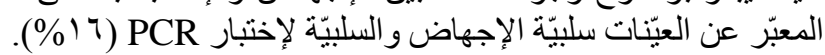

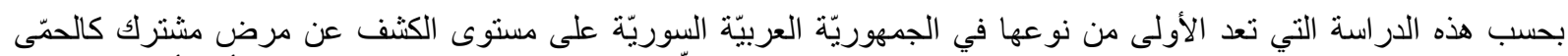

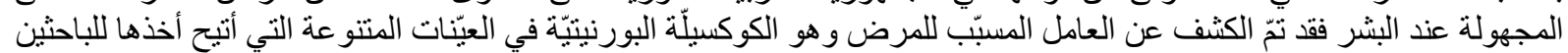

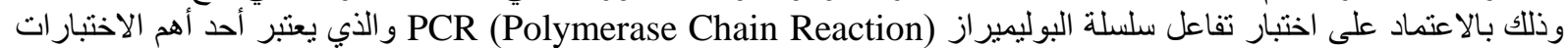

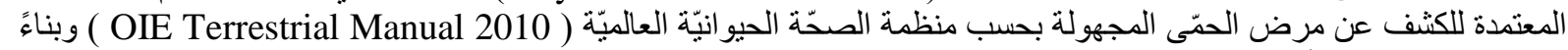

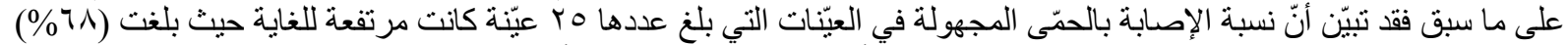

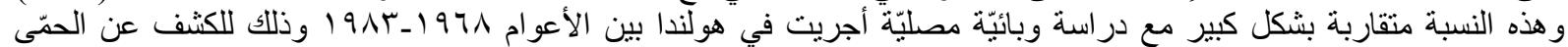

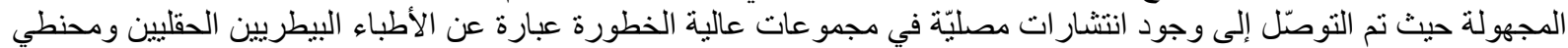

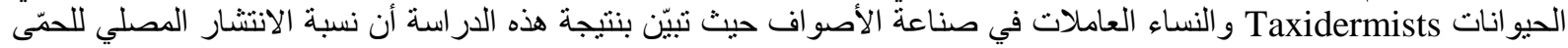

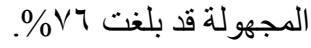

(Richardus et al., 1985; Houwers and Richardus, 1987; Richardus et al., 1987)

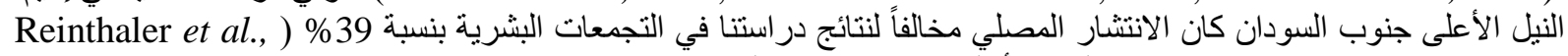

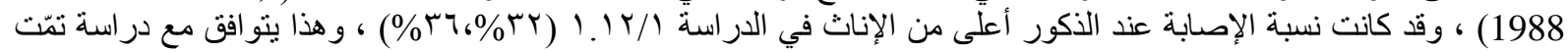

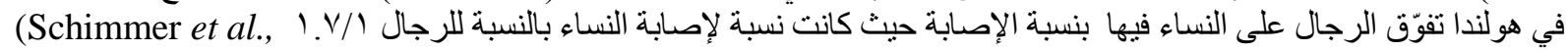

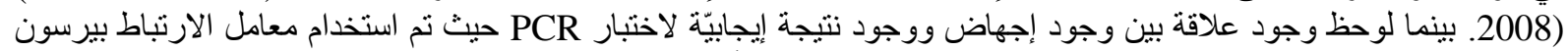
CORRELATIONS (PEARSON)

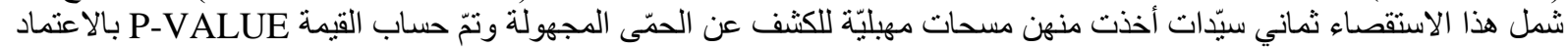

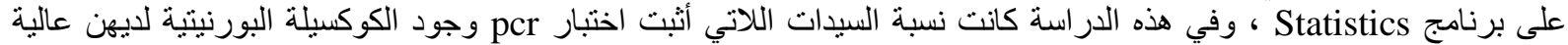

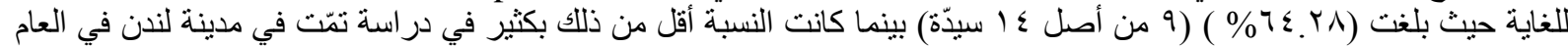

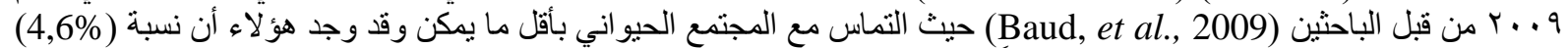

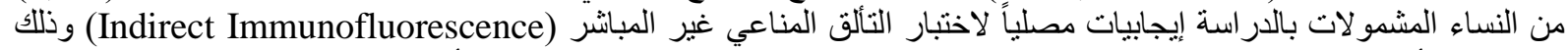

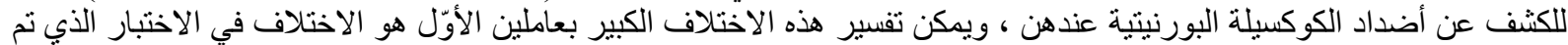

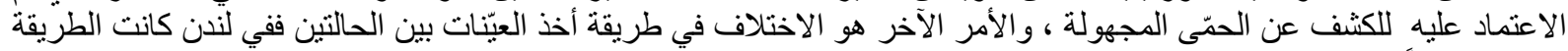
عشو ائيّة غالباً من نساء حوامل لاعلى التعين، وفي هذه الدراسة كانت العيّنات شبه مستهدفة.

\section{CONCLUSIONS and RECOMMENDATION الاستتتاجات و التوصيات}

مرض الحمى المجهولة الذي تسببه جر اثيم الكوكسيلة البورنيتية هو مرض موجود عند البشر في المنطقة الوسطى من القطر العربي السوري. نسبة انتشار المرض مرتفعة بشكل كبير وواضح. 


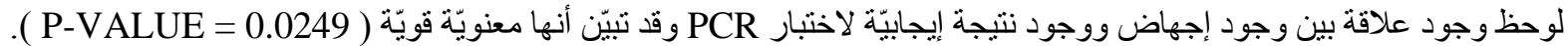

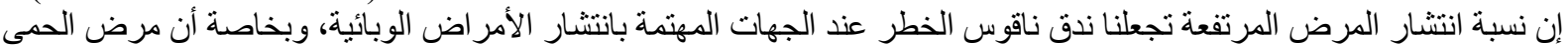

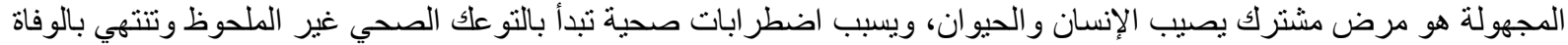
في بعض الحالات.

\section{REFERENCES}

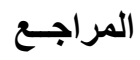

العمر أنور ـ التقصي المصلي عن وجود الكوكسيلا بورنيتي عند الأغنام في المنطقة الوسطى. بحث منشور في مجلّة جامعة البعث ، 11 ـــ.

Alsaleh, A.; Pellerin, J-L.; Rodolakis, A.; Larrat, M.; Cochonneau, D.; Bruyas, J-F. and Fieni, F. (2011): Detection of Coxiella burnetii, the agent of $\mathrm{Q}$ fever, in oviducts and uterine flushing media and in genital tract tissues of the non pregnant goat. Comp. Immunol. Microbiol. Infect. Dis, 34:355-360.

Alton, G.G.; Jones, L.M. and Pietz, D.E. (1975): Laboratory techniques in brucellosis. 2nd ed. World Health Organization. Geneva.

Alton, G.G.; Jones, L.M.; Angurs, R.D. and Verger, J.M. (1988): Techniques for the Brucellosis Laboratory. INRA. Paris, France.

Anette-Bфtner, Donald Broom;Marcus G. Doherr; Mariano Domingo,; Jörg Hartung; Linda Keeling; Frank Koenen; Simon More; David Morton; Pascal Oltenacu; Albert Osterhaus; Fulvio Salati; Mo Salman; Moez Sanaa; James M. Sharp; Jan A. Stegeman; Endre Szücs; Hans-H. Thulke; Philippe Vannier; John Webster and Martin Wierup (2010): EFSA (EUROPEAN FOOD SAFETY AUTHORITY). Panel on Animal Health and Welfare (AHAW); Scientific Opinion on Q Fever. EFSA Journal, 8 (5), 1595, 114 pp. doi: 10.2903/j.efsa. 2010.1595.

Arricau-Bouvery N. and Rodolakis A. (2005): Is Q fever an emerging or re-emerging zoonosis? Vet. Res., 3, 327-349.

Baud, O. Peter; Langel, C.; Regan, L. and Greub, G. (2009): Seroprevalence of Coxiella burnetii and Brucella abortus among pregnant women Journal Compilation (2009). European Society of Clinical Microbiology and Infectious Diseases, CMI, 15, 496-501.

Blasco, J.M. (1998): A review of the use of Coxiella burnetii Vaccine in adult sheep and goats. Prev. Vet. Med. 34: 160-183.

Boschini, A.; Di Perri, G. and Legnani, D. (1999): Consecutive epidemics of Q fever in a residential facility for drug abusers: impact on persons with human immunodeficiency virus infection. Clin Infect Dis; 28: 86672.

Carrieri, MP.; Tissot-Dupont, H. and Rey D. (2002): Investigation of a slaughterhouse-related outbreak of Q fever in the French Alps. Eur J Clin Microbiol Infect Dis; 21: 17-21.

Center of food security and public health studies, (2007): College of Veterinary Medicine lows state university Ames, lows 50011.1

De Alarcon, A.; Villanueva, JL. and Viciana, P. (2003): Q fever: epidemiology, clinical features and prognosis. A study from 1983 to 1999 in the South of Spain. J Infect; 47: 110-16.

Derrick, E. (1973): The course of infection with Coxiella burnetii. Med J Aust; 1: 1051-57.

Derrick E. and fever, $Q$. (1937): A new fever entity: clinical features, diagnosis and laboratory investigation. Med J Aust; 2: 281-99.

Dupuis, G.; Peter, O.; Pedroni, D. and Petite, J. (1985): Clinical aspects observed during an epidemic of 415 cases of Q fever. Schweiz Med Wochenschr;115: 814-8.

Dupuis, G.; Petite, J.; Peter, O. and Vouilloz, M. (1987): An important outbreak of human Q fever in a Swiss Alpine valley. Int J Epidemiol; 16: 282-87.

Fenollar, F.; Fournier, P.; Carrieri, MP.; Habib, G.; Messana, T. and Raoult, D. (2001): Risk factors and prevention of Q fever endocarditis. Clin Infect Dis; 33: 312-16.

Fournier, P.; Marrie, TJ. and Raoult, D. (1998): Diagnosis of Q Fever. J Clin Microbiol; 36: 1823-34.

Fournier, PE.; Etienne, J.; Harle, JR.; Habib, G. and Raoult D. Myocarditis (2001): A rare but severe manifestation of Q fever: report of 8 cases and review of the literature. Clin Infect Dis; 32: 1440-47.

Hilbink, F.; Penrose, M.; Kovacova, E. and Kazar, J. (1993): Q fever is absent from New Zealand. Int J Epidemiol; 22: 945-49.

Houwers, D.J. and Richardus, J.H. (1987): Infection with Coxiella burnetii in man and animals in the Netherlands. Zentralbl. Bakteriol. Mikrobiol. Hyg. A 267, 30-36.

Kermode, M.; Yong, K.; Hurley, S. and Marmion, B. (2003): An economic evaluation of increased uptake in Q fever vaccination among meat and agricultural industry workers following implementation of the National Q Fever Management Program. Aust N Z J Public Health; 27: 390-98. 
Lang, G.H. (1990): Coxiellosis (Q fever) in animals. In: Q Fever. Volume I: The Disease, Marrie T.J., ed. CRC Press, Boca Raton, USA, 23-48.

Lepidi, H.; Houpikian, P.; Liang, Z. and Raoult, D. (2003): Cardiac valves in patients with Q fever endocarditis: microbiological, molecular, histologic studies. J Infect Dis; 187: 1097-106.

Levy, PY.; Carrieri, P. and Raoult, D. (1999): Coxiella burnetii pericarditis: Report of 15 cases and review. Clin Infect Dis; 29: 393-97.

Marrie, T J. (2003): Coxiella burnetii pneumonia. Eur Respir J; 21(4): 713-9.

Marrie, TJ. and Raoult, D. (1997): Q fever-a review and issues for the next century. Int J Antimicrob Agents; 8: 145-61.

Maurin M. and Raoult D. (1999): Q fever. Clin. Microbiol. Rev., 12, 518-553.

McQuiston, JH. and Childs, JE. (2002): Q fever in humans and animals in the United States. Vector Borne Zoonotic Dis; 2: 179-91.

OIE Technical disease (2012): www.oie.int/en/animal health-in-the-world/technical-disease-cards/1.

OIE Terrestrial Manual (2010): Chapter 2.1.12. ; Q fever

Palmer, S R. and Young, S E J. (1982): Q fever endocarditis in Englandand Wales, 1975-1981. Lancet 2: 14481449.

Raoult, D. and Marrie, T. (1995): Q Fever. Clin Infect Dis; 20: 489-96.

Raoult, D.; Tissot-Dupont, H. and Foucault C. (2000): Q fever 1985-1998: Clinical and epidemiologic features of 1,383 infections. Medicine (Baltimore); 79: 109-23.

Raoult, D, Mege, JL. and Marrie, T. (2001): Qfever:Queries remaining after Decades of research, in S cheld WM, Craig WA, Hughes JM (eds): Emerging Infections 5. Washington, DC, AmericanSo-ciety of Microbiology Press, 26-56.

Raoult, D.Q. fever: (1996): still a query after all these years. J Med Microbi; 44: 77-78.

Reinthaler, F.F.; Mascher, F.; Sixl, W. and Arbesser, C/H. (1988): Incidence of Q fever among cattle, sheep and goats in the Upper Nile province in southern Sudan. Vet. Rec., 122(6): 137.

Richardus, J.; Donkers, A. and Dumas, A. (1987): Q fever in the Netherlands: a sero-epidemiological survey among human population groups from 1968 to 1983. Epidemiol Infect; 98: 211-19.

Richardus, J.; Dumas, A.; Huisman, J. and Schaap, G. (1985): Q fever in infancy: a review of 18 cases. Pediatr Infect Dis J; 4: 369-373.

Rolain, J.; Mallet, M. and Raoult, D. (2003): Correlation between serum doxycycline concentrations and serologic evolution in patients with Coxiella burnetii endocarditis. J. Infect Dis; 188: 1322-25.

Sawyer, L.; Fishbein, D. and McDade, J. (1987): Q fever: current concepts.Rev Infect Dis; 9: 935-46.

Schimmer, B.; Morroy, G.; Dijkstra, F.; Schneeberger, P.M.; Weers-Pothoff, G.; Timen, A.; Wijkmans, C. and van der Hoek, W. (2008): Large ongoing Q fever outbreak in the south of the Netherlands. Eur. Surveill. $13,18939$.

Sidi-Boumedine, K.; Rousset, E.; Henning, K.; Ziller, M.; Niemczuck, K.; Roest, H.I.J. and Thiery, R. (2010): Development of harmonised schemes for the monitoring and reporting of Q-fever in animals in the European Union. EFSA Scientific Report on Question No EFSA-Q-2009-00511., 48 pp.

Tissot-Dupont, H.; Raoult, D. and Brouqui, P. (1992): Epidemiologic features and clinical presentation of acute Q fever in hospitalized patients: 323 French cases. Am J Med; 93: 427-34.

Voth, D.E. and Heinzen, R.A. (2007): Lounging in a lysosome: The intracellular lifestyle of Coxiella burnetii Cellular Microbiology 9 (4): 1829-840.

Wilson, H.; Neilson, G.; Galea, E.; Stafford, G. and O'Brien, M. (1976): Q fever endocarditis in Queensland. Circulation; 53: 680-84. 